\title{
Physicochemical Transformation of Sulphur during Pharmaceutical Processing in Traditional Indian Medicine
}

\author{
M.R. RAJALAKSHMY*, C.V. SRUTHI, A.K. MANIYAN, S. VENDAMIRTHAM, P.T. NEERAJ AND A. SINDHU \\ R\&D Department, The Arya Vaidya Pharmacy (Coimbatore) Limited, Kanjikode West, Palakkad-678 623, India
}

Rajalakshmy, et al.: Sulphur Transformation during Pharma Processing

\begin{abstract}
The wide spectrum of biological properties of sulphur has resulted in its use in pharmaceutical industry, especially in the Indian Traditional Medicines, Ayurveda and Siddha. Native sulphur from rocks, volcanic deposits, hot springs, fossil mineral resources and salt domes has been traditionally used. In the pharmaceutical industry, sulphur is processed to remove elemental and molecular impurities. This purification is performed in Ayurveda through a simple process sodhana mentioned in Rasasastra, which would lead to interesting physicochemical transformations. This paper describes an attempt to evaluate the physical and chemical properties occurring in sulphur due to the sodhana process as well as removal of toxic impurities from native sulphur during this process. The changes to colour, appearance, odour, density, melting point, concentration and structure of sulphur were assessed using physicochemical methods, scanning electron microscopy, inductively coupled plasma mass spectrometry and $\mathrm{X}$-ray powder diffraction. The role of medium for incorporation of organic content was analysed by Fourier transform infrared spectroscopy.
\end{abstract}

Key words: Sulphur, structural changes, physicochemical changes, purification, X-ray diffraction, SEM, Rasasastra

Sulphur has a long history of use in science and medicine due to its wide spectrum of chemical and biological properties. In the pharmaceutical industry, sulphur finds use in the manufacture of organosulphur compounds, sulphonamides, which have antibacterial and antifungal properties. $\beta$-lactam antibiotics such as penicillins, cephalosporins, monolactams are popular.

Sulphur has been traditionally sourced from nature from volcanic rocks, geological fossils and salt domes, while industrially sulphur is obtained by refining of hydrocarbons. Naturally occurring sulphur compounds are sulphides of mercury (cinnabar), antimony (stibnite), lead (galena), iron (pyrite) and zinc (sphalerite), sulphates of calcium (gypsum), barium (barite) and potassium (alunite) ${ }^{[1]}$. Sulphur used in pharmaceutical preparations is therefore subject to processes aimed at removal of impurities including metals and other harmful compounds though these may be present in very small concentrations ${ }^{[2]}$. Arsenic is one of the major impurities found in sulphur ${ }^{[3]}$.

There are different processes recommended or adapted for purification process in metallurgy ${ }^{[4]}$. For pharmaceutical preparations using sulphur in the Indian

*Address for correspondence E-mail: mrrajisuresh@gmail.com

September-October 2017
Tradition Medicine, Ayurveda, a variety of methods have been employed, one of which was the sodhana process as described in the classical text Rasasastra ${ }^{[5]}$. Sodhana also referred to as purification or detoxification process, is believed to result in elimination of impurities, lessening of toxicity, reduction in hardness of material and potentiating therapeutic efficacy ${ }^{[6]}$. As per Rasasasthra, internal consumption of raw sulphur (unpurified) produced discomfort, allergies, increased body temperature and caused diseases of blood, skin and pitta disorders that resulted in destruction of body similar to poisons. Hence purification is carried out to improve quality of sulphur. Purified sulphur could improve health, treat skin-related and pitta-related disorders. Purified sulphur is used for preparation of many potent traditional medicines like kajjali, rasasindhoor, and gandhakarasayanam.

This is an open access article distributed under the terms of the Creative Commons Attribution-NonCommercial-ShareAlike 3.0 License, which allows others to remix, tweak, and build upon the work non-commercially, as long as the author is credited and the new creations are licensed under the identical terms

Accepted 31 July 2017

Revised 19 February 2017

Received 25 August 2016

Indian J Pharm Sci 2017;79(5):794-800 
Research studies on the process of purification of sulphur focused mainly on purity assessment of sulphur, before and after processing, including changes to physical properties ${ }^{[7,8]}$. The objective of this study was to evaluate changes in physical and chemical properties of sulphur when subjected to the sodhana purification process, formation of organic sulphur compounds and evaluation of the role of medium used in the bioprocessing especially with reference to reduction in concentration of heavy metals and other impurities for the final processed sulphur compared to starting sample.

\section{MATERIALS AND METHODS}

Samples of sulphur were collected from an Ayurvedic industry, M/s. Arya Vaidya Pharmacy Limited, Coimbatore, India. The sulphur samples were subjected to one of the most commonly used sodhana purification processes as described in Rasasastra ${ }^{[9,10]}$.

\section{Procedure for sodhana purification process:}

Cream prepared from unboiled cow's milk was churned, separated from its liquid residue and simmered over low heat to prepare clarified butter, known as ghee. A sample of sulphur was collected for physicochemical analysis. Sulphur was then subject to the sodhana process as described below. About $300 \mathrm{~g}$ of raw sulphur was added to an equal amount of ghee into a steel pan on a stove and heated slowly to melt. The molten sulphur was then poured onto an earthen pot containing about $500 \mathrm{ml}$ of cow milk and set to cool. The solidified sulphur so formed was removed from the ghee-milk mixture through cotton-fabric sieve and gently washed with warm water. Samples of ghee-milk mixture and the dry sulphur were collected for physicochemical analysis. The solidified sulphur was again added to fresh ghee and the sulphur melting-washing cycle was repeated (fig. 1). This was performed seven times, as described in the classical text, Rasasastra, for the sodhana process. The samples of sulphur and ghee-milk mixture were collected for analysis at the end of each of the seven cycles.

\section{Physicochemical analyses:}

The sulphur samples collected before and after each cycle of the sodhana process were evaluated for properties such as colour, appearance, odour, density and melting point. Concentration of sulphur in samples collected before and after the sodhana process was determined by inductively coupled plasma atomic emission spectroscopy (ICP-AES) method. Physical changes in structure, molecular arrangement and compound formation for both samples were determined using powder X-ray diffraction on a diffractometer (Bruker AXS-D8 Avance). The scans were recorded from 3 to $80^{\circ}$ with step size of $0.020^{\circ}$ at step time $65.6 \mathrm{~s}$, using copper radiation and silicon lithium position sensitive detector (PSD).

Detailed surface morphology study for the two sulphur samples was carried out using scanning electron microscopy (SEM, Jeol JSM 6390LV). Sulphur samples were mounted over a double sided adhesive tape for the analysis. Sulphur samples from before and after sodhana were mixed with $\mathrm{KBr}$ and their Fourier transform infrared (FTIR) spectra obtained using FTIR spectrophotometer (Bruker) over the range 500 to $4000 \mathrm{~cm}^{-1}$. The objective of this analysis was detection of any new peaks corresponding to organic group attached with sulphur or their compound formation.

Samples of milk used were also analysed for sodhanainduced changes to their physical properties. Parameters such as $\mathrm{pH}$, total solids, ash values and acid insoluble ash percentages were determined after each iteration cycle during the sodhana process. Samples of milk and ghee collected on each day after processing were pooled and analysed for the presence of heavy metal, arsenic. Arsenic was considered as a lipid soluble impurity and usually associated with sulphur from most sources such as ores. The assessment for arsenic was done by ICP-AES method. FTIR spectroscopy was also performed on milk to detect the presence of active functional groups associated with milk and understand their probable transfer to sulphur due to sodhana process.

\section{RESULTS AND DISCUSSION}

The physicochemical studies on sulphur samples collected before and after purification by sodhana revealed considerable differences in colour, appearance and odour, as described in Table 1. The density of sulphur was observed to have lowered from 2.07 to $1.95 \mathrm{~g} / \mathrm{cc}$ while there was an observed change in melting point from 96 to $110^{\circ}$ using melting point apparatus.

The results from physicochemical analysis carried out on samples of milk-ghee mixture collected at end of each cycle were given in Table 2. The variations in parameters such as $\mathrm{pH}$, total solids, ash value, acid insoluble ash, etc. were observed in Table 2. The $\mathrm{pH}$ for ghee-milk sample from initial purification indicated a large deviation from that for original fresh 

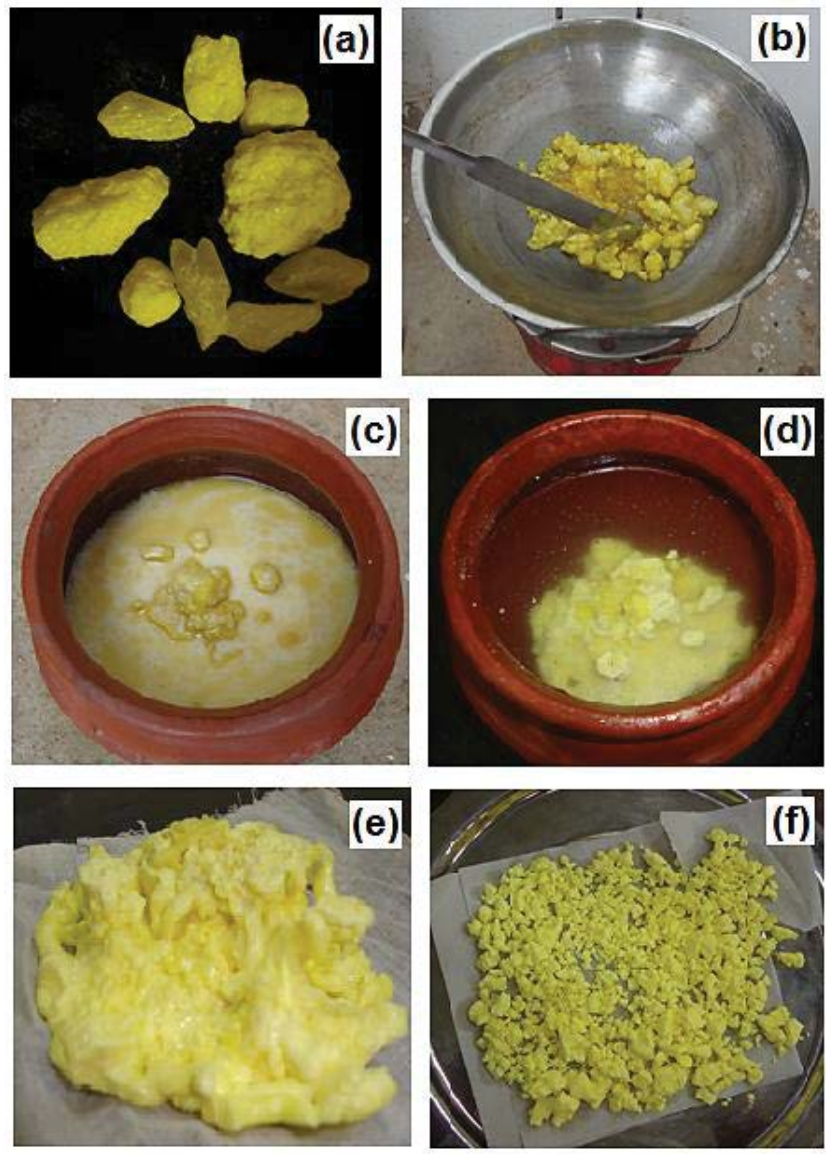

Fig. 1: One cycle in sodhana process

(a) Raw sulphur, (b) melting with ghee, (c) molten mixture in milk, (d) settling of mixture, (e) filtered sulphur, (f) dried sulphur

TABLE 1: PHYSICOCHEMICAL CHARACTERS OF SULFUR BEFORE AND AFTER SODHANA PROCESS

\begin{tabular}{|c|c|c|}
\hline Characters & Raw sulphur & Processed sulphur \\
\hline Colour & Shiny yellow & Yellow \\
\hline Appearance & $\begin{array}{l}\text { Highly crystalline, } \\
\text { Sharp and shiny } \\
\text { appearance }\end{array}$ & $\begin{array}{l}\text { Amorphous, not } \\
\text { Sharp, no shiny } \\
\text { appearance }\end{array}$ \\
\hline Texture & Hard, rough & Soft, smooth \\
\hline Smell & Foul & No foul smell \\
\hline Density (g/cc) & 2.07 & 1.95 \\
\hline Melting point $\left({ }^{\circ}\right)$ & 96.0 & 110.0 \\
\hline
\end{tabular}

The physicochemical studies revealed considerable differences in colour, appearance and odour. The density of sulphur was observed to have lowered from 2.07 to $1.95 \mathrm{~g} / \mathrm{cc}$ while there was an observed change in melting point from 96 to $110^{\circ}$ sample of ghee-milk mixture. However, with repeated purification cycles, deviation in $\mathrm{pH}$ was observed to be reducing compared with pure sample. The same trend was observed for other parameters: total solids and ash percentage. These parameters were found to be at higher concentrations in initial ghee-milk sample and thereafter gradually reducing as purification process is repeated. Concentration of arsenic in milk samples, from before and after processing indicated reduction in concentration of sulphur compared with raw sulphur sample. Though arsenic concentration in initial sample of cow's milk and ghee were undetectable, analysis showed a high concentration in the residual ghee-milk mixture (Table 3 ).

The percentage of sulphur was analysed in samples collected before and after the sodhana. There was a marked decrease in sulphur concentration after processing. The FTIR spectra of sulphur before and after purification were shown in fig. $2 \mathrm{~A}$ and $2 \mathrm{~B}$, respectively. The FTIR spectrum was also determined for the pooled ghee-milk sample as shown in fig. $2 \mathrm{C}$. The fingerprint region, $1400 \mathrm{~cm}^{-1}$ to $900 \mathrm{~cm}^{-1}$, for processed sulphur was observed to have a complex form compared to that for raw sulphur, which is indicative of presence of organic groups. The appearance of new absorption peaks at wavelengths $1375,1240,1164$ and $720 \mathrm{~cm}^{-1}$ in the spectrum of processed sulphur confirm presence of different organic groups. The absorption bands at wavelengths 2924, 1462, 1380 and $1375-1173 \mathrm{~cm}^{-1}$ are ascribed to methyl groups and stretching vibrations of sulphonyl groups respectively. The presence of multiple $\mathrm{C}=\mathrm{O}$ groups at the absorption band $1240 \mathrm{~cm}^{-1}$ was confirmed ${ }^{[11]}$. This could also explain for reduction in concentration of sulphur at the end of sodhana process.

The X-ray powder diffraction (XRD) patterns for the sulphur samples were shown in fig. 3 . The $2 \theta$ values were observed in the range 23.74 to $29.34^{\circ}$, typical of alpha sulphur, and were present in both patterns. The highly intense peak at $2 \theta$ of 52.7 for a $d=7.14$ as observed in XRD pattern of raw sulphur were found to

TABLE 2: RESULTS OF PHYSICOCHEMICAL ANALYSIS FOR MILK DURING SODHANA

\begin{tabular}{lcccccccc}
\hline \multirow{2}{*}{ Tests } & Before & \multicolumn{5}{c}{ After N ${ }^{\text {th }}$ cycle of sodhana process } \\
\cline { 5 - 9 } & sodhana & 1 & 2 & 3 & 4 & 5 & 6 \\
\hline $\mathrm{pH}$ & 6.97 & 6.42 & 6.50 & 6.59 & 6.63 & 6.67 & 6.70 & 6.78 \\
Total solids (\%) & 14.26 & 17.51 & 15.41 & 14.96 & 14.84 & 14.63 & 14.54 & 14.38 \\
Ash value (\%) & 0.627 & 0.794 & 0.758 & 0.756 & 0.752 & 0.749 & 0.743 & 0.732 \\
Acid insoluble ash value (\%) & 0.001 & 0.034 & 0.020 & 0.175 & 0.150 & 0.146 & 0.134 & 0.128 \\
\hline
\end{tabular}

Samples of milk-ghee mixture collected at end of each cycle. The variations in parameters such as pH, total solids, ash value and acid insoluble ash were observed 
TABLE 3: PHYSICO-CHEMICAL CHARACTERS OF SULFUR

\begin{tabular}{lcc}
\hline Assay & $\begin{array}{c}\text { Before } \\
\text { processing }\end{array}$ & $\begin{array}{c}\text { After } \\
\text { processing }\end{array}$ \\
\hline $\begin{array}{l}\text { Sulphur concentration (\%) } \\
\text { Arsenic concentration (in } \\
\text { milk-ghee mixture } \mathrm{mg} / \mathrm{kg})\end{array}$ & 99.52 & 98.61 \\
\hline
\end{tabular}

Concentration of arsenic in milk samples, from before and after processing indicated reduction in concentration of sulphur compared with raw sulphur sample. Though arsenic concentration in initial sample of cow's milk and ghee were undetectable, analysis showed a high concentration in the residual ghee-milk mixture diminish to an intensity of 200 Lin counts in processed sulphur. The SEM images of sulphur samples before and after processing are represented in fig. 4. The SEM images indicate surface profile changes. An extraneous particle present on the SEM surface image for raw sample was found to be absent in the processed sample.

Changes in colour, texture and appearance of processed sample provided preliminary confirmation of physical changes that occurred with raw sulphur during the sodhana process. The density and melting point details

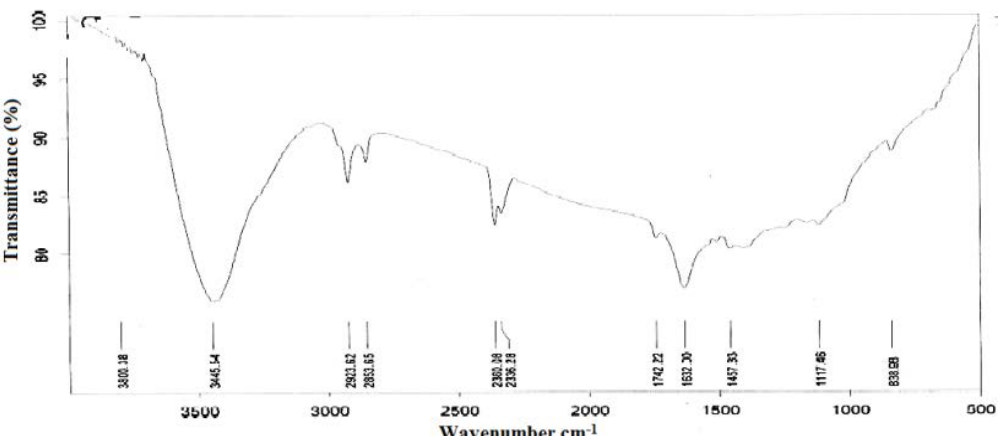

A.

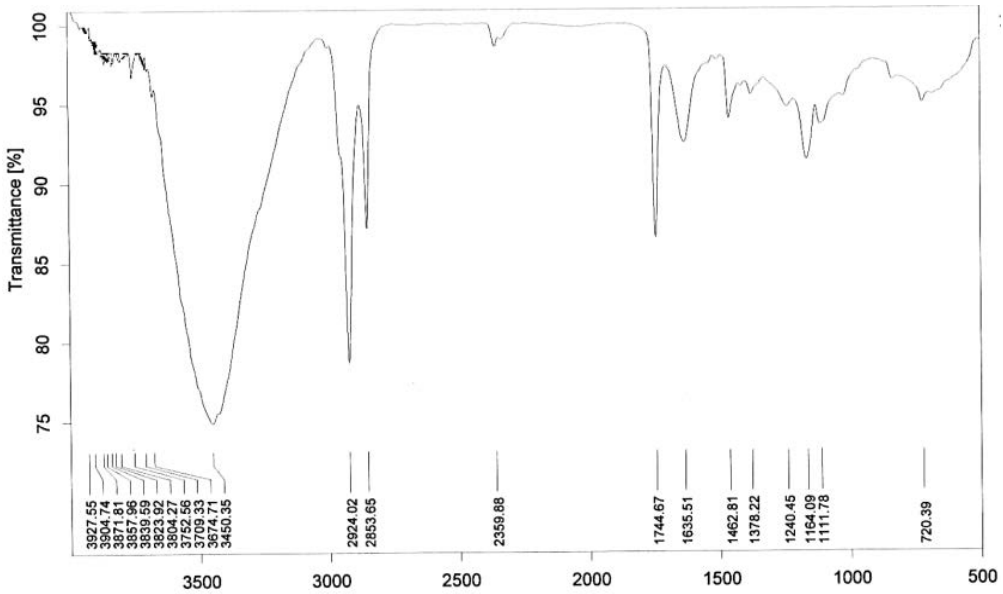

B.

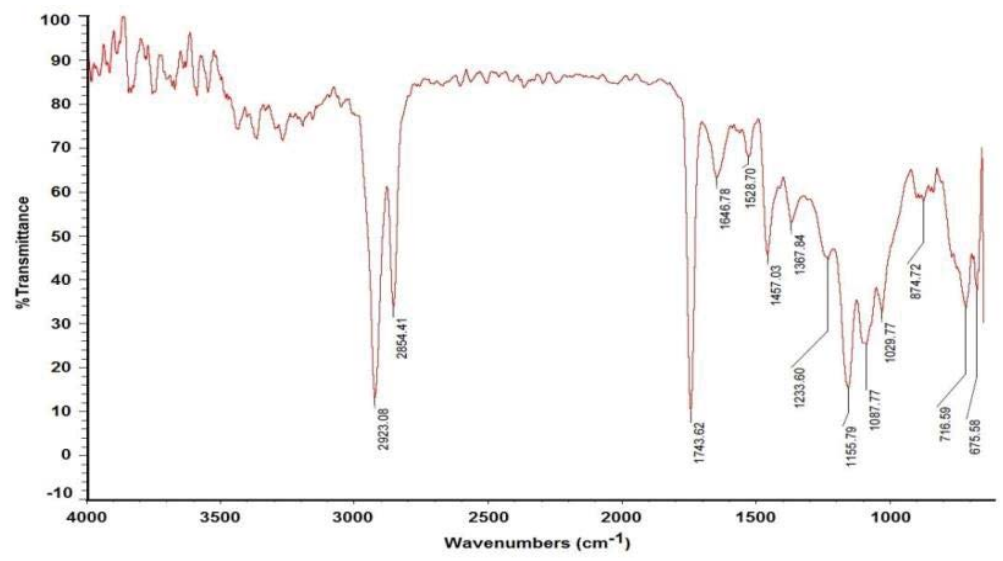

Fig. 2: FTIR spectrum of Sulphur before process (A), after process (B), milk (C)

The fingerprint region, $1400 \mathrm{~cm}^{-1}$ to $900 \mathrm{~cm}^{-1}$, for processed sulphur was observed to have a complex form compared to that for raw sulphur, which is indicative of presence of organic groups. The appearance of new absorption peaks at wavelengths 1375, 1240,1164 and $720 \mathrm{~cm}^{-1}$ in the spectrum of processed sulphur confirm presence of different organic groups. The absorption bands at wavelengths 2924, 1462, 1380 and $1375-1173 \mathrm{~cm}^{-1}$ are ascribed to methyl groups and stretching vibrations of sulfonyl groups, respectively 


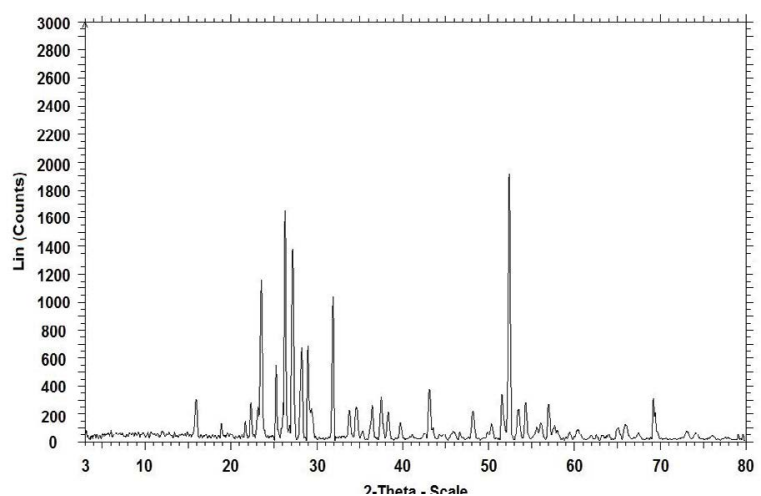

A.

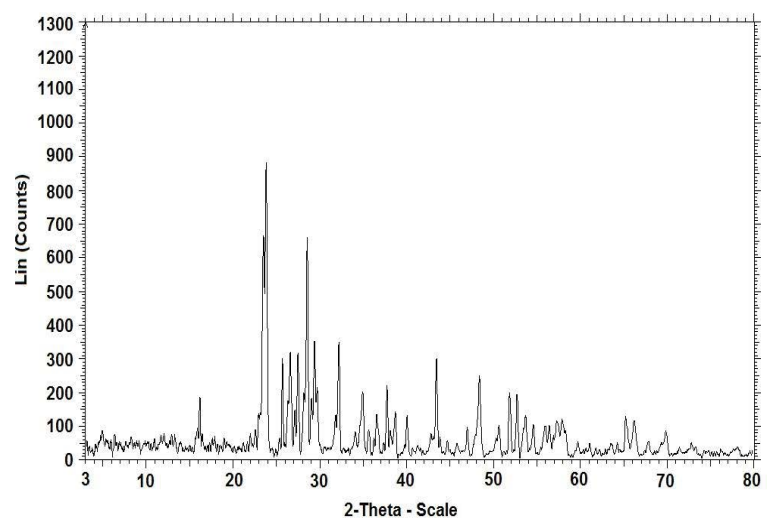

Fig. 3: XRD spectrum of sulphur before process (A) after process (B)

The $2 \theta$ values were observed in the range 23.74 to $29.34^{\circ}$, typical of alpha sulphur, and were present in both patterns. The highly intense peak at $2 \theta$ of 52.7 for a $d=7.14$ as observed in XRD pattern of raw sulphur were found to diminish to an intensity of 200 Lin counts in processed sulphur
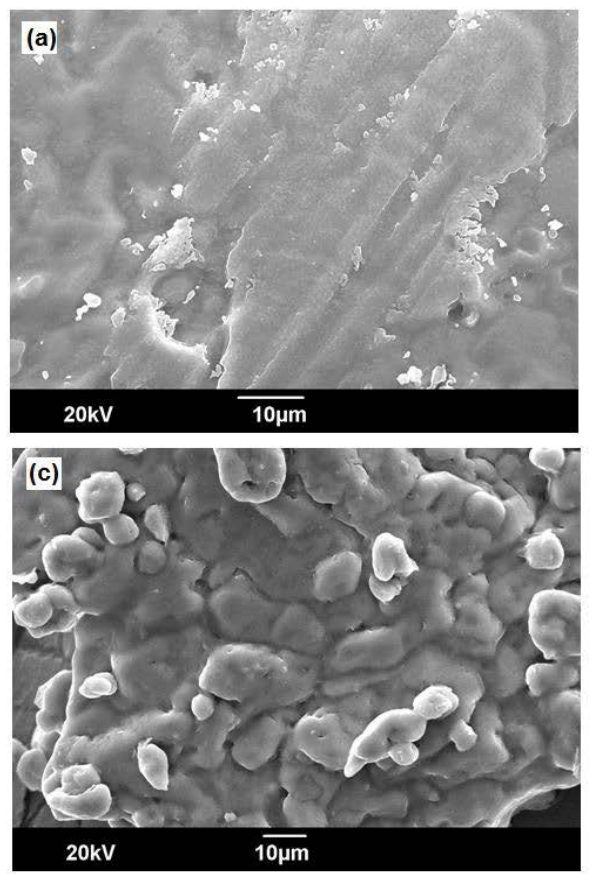

concerning raw sulphur indicate to the $\alpha$-form while those information for processed sample point to their $\beta$ - form ${ }^{[12]}$. The variation in density and melting point indicate possible change to allotropic form of sulphur. Studies revealed that during melting the molecule opens the chain structure ${ }^{[13,14]}$. The decrease in the sulphur concentration in processed sample could be due to the incorporation of organic compounds to its active ends when the chain structure opens as a result of solidification of molten sulphur in milk. This was again confirmed by the presence of organic groups like sulphonyl and carbonyl in the fingerprint region of the processed sample. Since fingerprint region in FTIR spectrum is very specific to any compound, difference in spectrum for both sulphur samples indicate physical changes. The appearance of new peaks in FTIR spectrum of processed sulphur may be attributed to effect of ghee-milk mixture on sulphur during the processing, since presence of these bands were observed for FTIR spectrum of initial milk sample. The difference in FTIR spectra for processed and raw sulphur could be due to migration of organic groups from milk and resulting compound formation with sulphur.

The powder XRD data indicates the nature of crystal characters for substances. The XRD pattern for both raw and processed sulphur were complex, thereby indicating presence of various crystal forms. The presence of alpha form was identified in both the
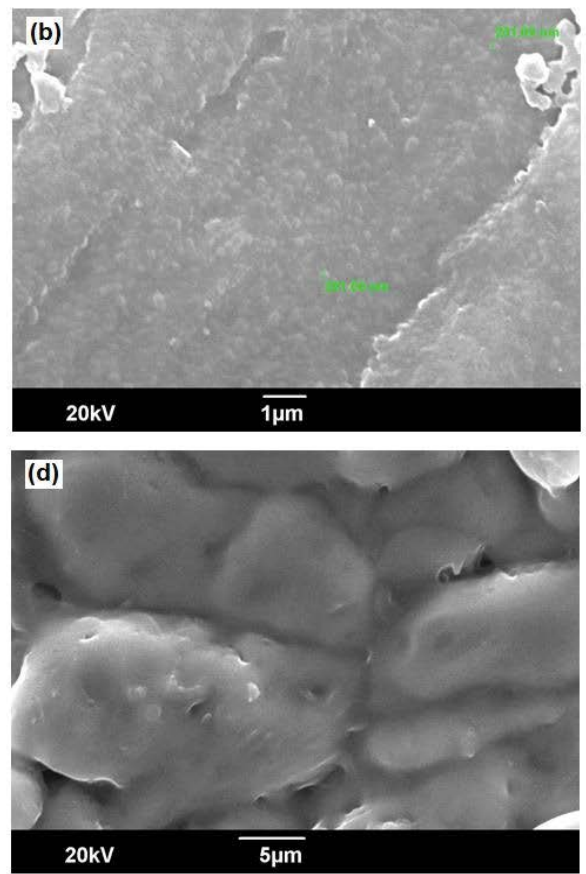

Fig. 4: SEM of raw and processed sulphur

(a, b) SEM of raw sulphur and (c, d) processed sulphur. The SEM images indicate surface profile changes. An extraneous particle present on the SEM surface image for raw sample was found to be absent in the processed sample 
samples $^{[15]}$, and it was also observed that sulphur existed in the processed sample both in its elemental and compound forms. The change in intensity of peak in XRD pattern for processed sulphur was associated with physical rearrangement of atoms such as additional bonding to other atoms. The SEM images for both samples reveal changes in surface morphology. Very sharp and crystalline surface was observed for raw sample and these were observed to have changed to very soft surface. Extraneous particles were absent in processed sulphur compared to their presence in raw samples (at $201.00 \mathrm{~nm}$ ).

The physicochemical analysis on ghee-milk mixture showed variations in ash percentage, total solids and $\mathrm{pH}$, indicating possible leaching of chemical components including arsenic, from raw sulphur into the medium during sodhana process. The high arsenic concentration in ghee-milk pooled mixture obtained through the sodhana process points to the important role of media in sodhana. Arsenic, being lipid soluble, are expelled by ghee.

The milk in the medium, solidifies molten sulphur and is likely to have formed into micro emulsion. Micro emulsions have been employed to increase solubility of many water insoluble drugs for transdermal use ${ }^{[16]}$. Studies report on medicines for treatment of skin diseases prepared from sulphur and processed using fat media $^{[17]}$. The presence of sulphonyl group may contribute to therapeutic property since sulphonyl group containing compounds constitute one among an important class of therapeutic agents in medicinal chemistry ${ }^{[18]}$.

The study confirms physicochemical changes occurring in sulphur when subjected to sodhana process. The reduction in concentration of heavy metals during sodhana though leaching, allotropy changes to sulphur making it softer, and reduction in odour were the prime changes observed from the study. The presence of organic groups like sulphonyl and carbonyl in fingerprint region of FTIR in the processed sample confirm role of media in enhancement of pharmaceutical activity for sulphur. The study helped understand variations to physicochemical parameters during each cycle of sulphur processing besides confirming for presence of different organic groups from ghee-milk mixture forming compounds with sulphur.

\section{Acknowledgements:}

The authors appreciate the technical advice and support provided by Dr. N. P. Damodaran of The International
Institute of Ayurveda. The authors are also thankful to the management of Arya Vaidya Pharmacy (Coimbatore) for the support provided for the research and analytical work.

\section{Financial assistance:}

Nill.

\section{Conflicts of Interest:}

The authors declare no conflicts of interest.

\section{REFERENCES}

1. Kutney G. Sulfur: History, Technology, Applications \& Industry. 2nd ed. Toronto: ChemTec Publishing; 2013.

2. Bacon RF, Fenneti R. Purification of Sulfur. J Ind Eng Chem 1942;34:1043-8.

3. Wadodkar DS, Bhagwanrao SS. Observational study of gandhak shodhan process of Ayurved prakash and rasayansar method. Int Ayurvedic Med J 2015;3:2729-33.

4. Damste' JSS, Rijpstra WIC, Dalen ACK, Leeuw JWD, Schenk PA. Quenching of labile functionalized lipids by inorganic sulphur species: evidence for the formation of sedimentary organic sulphur compounds at the early stages of diagenesis. Geochim Cosmochim Acta 1989;53:1343-55.

5. Sharma S. Rasatharangini. 2nd ed. New Delhi: Motilal Banarsidass Publishers Pvt. Ltd.; 1971. p. 176-7.

6. Chaube A, Prajapathi PK, Dixit SK. On the technique of sodhana. Anc Sci Life 1996;17:67-73.

7. Bhandari S, Bhadra Dev P, Murthy PHC. Sodhana of gandhaka (sulphur) with godugdha (cow's milk), gogrutha (cow's ghee): a chemical analysis. J Pharm Sci Innovation 2013;2:70-2.

8. Shanmugapriy $\mathrm{P}$, Christian GJ, Vajrai R, Brindha P, Elansekaran S, Murugesan M, et al. Antimicrobial efficacy of Gandhagam (raw sulphur), purified Gandhagam and Gandhaga Mezhugu - a traditional Siddha formulation. J Pure Appl Microbiol 2013;7:1-4.

9. Kulkarni DA. Acharya Vagbhatta, Rasaratna samuchaya (Translation). New Delhi: Meharchand Publications; 2006. p. 45-6.

10. Acharya YT. Rasamritam. 1st ed. Varanasi: Chaukhambha Sanskrit Sansthan; 2007. p. 29-30.

11. Mohan J. Organic Spectroscopy Principle and Applications. 2nd ed. New Delhi: Narosa Publishing House Pvt. Ltd.; 2007.

12. Maryadele J. O'Neil. The Merck Index, an Encyclopedia of Chemicals, Drugs and Biological. 14th ed. Whitehouse Station, NJ: Merck; 2006.

13. Winter R, Egelstaff PA, Pilgrim WC, Howells WC. The structural properties of liquid and quenched sulphur. J Phys 1990;2:215-8.

14. Černošek Z, Holubová J, Černošková E, Růžička A. Sulfur a new information on this seemingly well-known element. J Non-Oxide Glasses 2009;1:38-42.

15. Gang Liu, Ping Niu, Lichang Yin, Hui-Ming Cheng. $\alpha$-Sulphur crystals as a visible light active photocatalyst. J Am Chem Soc 2012;34:9070-3. 
16. Choudhari A, Nagaich U, Neha Gulati, Sharma VK, Khosa RL. Enhancement of solubilization and bioavailability of poorly soluble drugs by physical and chemical modifications: A recent review. J Adv Pharm Educ Res 2012;2:32-67.
17. Damodar J. Concept of Ayurvedic sodhana method and its effects with reference to sulphur. Anc Sci Life 1982;1:229-35.

18. Stephen WP. Sulphur in Human nutrition and applications in medicine. Altern Med Rev 2002;7:1-35. 